\title{
Histological confirmation of needle tip position during ultrasound-guided interscalene block: a randomized comparison between the intraplexus and the periplexus approach Confirmation histologique de la position de l'extrémité d'une aiguille au cours d'un bloc interscalénique échoguidé: une comparaison randomisée comparaison entre l'approche intraplexique et périplexique
}

\author{
Jennifer J. Szerb, MD • Justin L. Greenberg, MDCM • M. Kwesi Kwofie, MD • \\ William H. Baldridge, PhD $\cdot$ Robert E. Sandeski $\cdot$ Juan Zhou, PhD $\cdot$ Kim Wong, MD \\ Received: 16 January 2015/Revised: 20 July 2015/Accepted: 20 August 2015 / Published online: 3 September 2015 \\ (C) Canadian Anesthesiologists' Society 2015
}

\begin{abstract}
Purpose Ultrasound-guided interscalene block can be performed using either periplexus or intraplexus needle placement. In this novel study, we histologically examined the needle tip position in relation to the neural tissues with the two techniques. Our objective was to investigate the variable risk of subepineurial needle tip placement resulting from the two ultrasound-guided techniques.

Methods In an embalmed cadaveric model, periplexus or intraplexus interscalene injections were performed with the side, order, and technique assigned randomly. Under real-
\end{abstract}

This study was submitted as an abstract for presentation at the ASRA Regional Anesthesiology and Acute Pain Medicine Meeting in Las Vegas in May 2015. The abstract was awarded a "Best of Meeting Abstract Award" at that meeting.

Author contributions Jennifer J. Szerb conceptualized the study and did background research for the study. She participated in the laboratory in both the pilot and main experiment, analyzed data, and made major contributions to manuscript preparation. Justin $L$. Greenberg performed all ultrasound-guided needle passes for the main study and was involved in data collection, analysis, and storage. M. Kwesi Kwofie was involved in conceptualization of the study question, design, data analysis, statistical support, and manuscript writing. William H. Baldridge was involved in the provision of laboratory space, assistance in obtaining materials and cadavers, histology, and photography of histology slides. He provided expertise in neuropathology to assist in slide interpretation, and manuscript editing. Robert E. Sandeski was the expert in cadaver dissection and performed all dissections in the study; as chief embalmer, he was instrumental in providing high-quality cadavers and transporting them to the laboratory. Juan Zhou was involved in organizing the experiment, contributed to procedure development, and edited the manuscript. Kim Wong conceptualized, performed, and analyzed the pilot study. time ultrasound guidance, the block needle was placed next to the hyperechoic layer of the plexus (periplexus) or between the hypoechoic nerve roots (intraplexus). Once positioned, $0.1 \mathrm{~mL}$ of black acrylic ink was injected. The brachial plexus tissues were then removed and histology sections were prepared and then coded in order to blind two reviewers to group allocation. The area of ink staining was used to determine needle tip location, and the groups were compared for the presence of subepineurial ink.

Results Twenty-six cadavers had each of the blocks performed on either brachial plexus (i.e., 52 injections). No

Electronic supplementary material The online version of this article (doi:10.1007/s12630-015-0468-y) contains supplementary material, which is available to authorized users.

J. J. Szerb, MD ( $\varangle)$ · J. L. Greenberg, MDCM ·

M. K. Kwofie, MD

Department of Anesthesia, Pain Management and Perioperative

Medicine, QEII Health Science Centre, Dalhousie University,

Victoria General Site, 10 West Victoria, 1276 South Park St.,

Halifax, NS B3H 2Y9, Canada

e-mail: szerbj@ns.sympatico.ca

W. H. Baldridge, $\mathrm{PhD}$ - R. E. Sandeski

Department of Medical Neuroscience, Dalhousie University,

Halifax, NS, Canada

J. Zhou, PhD

Departments of Anesthesia, Microbiology and Immunology,

Dalhousie University, Halifax, NS, Canada

K. Wong, MD

Department of Anesthesia, Northern Ontario School of

Medicine, Health Sciences North, Sudbury, ON, Canada 
subepineurial ink deposits were observed in the periplexus group (0\%), but subepineurial ink deposition was observed in 3/26 (11.5\%) intraplexus injections (odds ratio, 0; 95\% confidence interval, 0 to 2.362; $P=0.235$ ). Furthermore, in the intraplexus group, two (of the three) subepineurial ink deposits were observed under the perineurium.

Conclusion Although our study was somewhat underpowered due to a lower than previously reported rate of subepineurial needle tip positioning, our results suggest that there may be an increased likelihood of subepineurial needle tip position with the intraplexus approach. The periplexus technique resulted in no subepineurial spread of ink, suggesting that this approach may be less likely to result in mechanical trauma to nerves from direct needle injury.

\section{Résumé}

Objectif Le bloc interscalénique échoguidé peut être réalisé par la mise en place d'une aiguille périplexique ou intraplexique. Dans cette étude originale, nous avons procédé à un examen histologique de la position de la pointe de l'aiguille selon les deux techniques par rapport au tissu nerveux. Notre objectif était d'analyser le risque variable de positionnement sous-épineural de l'extrémité de l'aiguille dans le cas des deux techniques échoguidées. Méthodes Des injections interscaléniques péri et intraplexiques ont été réalisées sur un modèle cadavérique embaumé; le côté, l'ordre et la technique de réalisation ont été assignés de manière aléatoire. L'aiguille du bloc a été placée sous guidage échographique en temps réel à proximité de la zone hyperéchogène du plexus (périplexique) ou entre les racines nerveuses hyperéchogènes (intraplexique). Une fois l'aiguille en place, 0,1 mL d'encre acrylique noire a été injecté. Les tissus du plexus brachial ont été ensuite prélevés; des coupes histologiques ont été préparées puis codées afin que les deux examinateurs restent dans l'ignorance de l'assignation à un groupe particulier. La zone de coloration par l'encre a permis de déterminer l'emplacement de la pointe de l'aiguille et la comparaison entre les groupes a porté sur la présence d'encre sous-épineurale.

Résultats Chaque type de bloc a été pratiqué sur chaque plexus brachial de 26 cadavres (soit un total de 52 injections). Aucun dépôt d'encre n'a été observé dans le groupe périplexique $(0 \%)$, mais un dépôt d'encre sous-épineural a été observé dans 3 des 26 injections intraplexiques (11,5\%) (rapport de cotes, 0 ; intervalle de confiance à $95 \%: 0$ à 2,362; $P=0,235)$. En outre, dans le groupe intraplexique, deux (sur les trois) dépôts d'encre sous-épineural ont été constatés sous le périnèvre.

Conclusion Même si notre étude a quelque peu manqué de puissance en raison d'un taux de placement sous-épineural de l'aiguille inférieur aux publications antérieures, nos résultats laissent penser que la probabilité du placement sous-épineural de l'extrémité de l'aiguille est plus importante avec un abord intraplexique. La technique périplexique n'a donné lieu à aucune diffusion sous-épineurale de l'encre, suggérant que cet abord est susceptible d'entraîner moins de traumatismes mécaniques des nerfs par lésion directe due à l'aiguille.

The introduction of ultrasound technology to the practice of regional anesthesia has not resulted in a reduction in the rate of neurological injury. ${ }^{1,2}$ This may be due to the limitation of conventional ultrasound to distinguish muscle fascia from epineurium and small fascicles, ${ }^{3-5}$ such that mechanical nerve injury, barotrauma, or local anesthetic toxicity may result from unintended injection into critical nerve structures. ${ }^{1,6-10}$ This has recently led investigators to focus on how best to avoid nerves while still achieving a reliable block. No difference in block quality or onset time occurred when comparing a periplexus with an intraplexus technique for brachial plexus block at the interscalene groove. ${ }^{11}$ Recently, a 95\% success rate was achieved when interscalene nerve block was performed by positioning the needle $1.6 \mathrm{~mm}$ from the lateral border of the roots within the middle scalene muscle. This suggests that high efficacy regional anesthesia can be achieved even by means of intramuscular needle placement without directly targeting nerves. ${ }^{12}$

At the interscalene level of the brachial plexus, the commonly accepted intraplexus technique is to place the needle tip beyond the fascia of the middle scalene muscle between the hypoechoic roots or trunks. This space is argued to be safe based on the anatomical finding that each root is surrounded by its own investing epineurium. ${ }^{13}$ An injection between roots or trunks would therefore be extra-epineurial. ${ }^{14}$ The safety of the intraplexus technique was questioned in a cadaver study when the ink deposits were observed below the epineurium in five of the ten injections (50\%) using an intraplexus ultrasound technique. ${ }^{15}$ There is a minimal amount of connective tissue around the brachial plexus at the interscalene level; therefore, a 50\% chance of subepineurial injection may suggest a high probability of direct mechanical injury by the needle tip, which can result in undesired neurological complications. ${ }^{16}$ Nevertheless, this study was a small observational study, and we did not look for the incidence of subepineurial injection with an alternate technique.

In this present study, we aimed to clarify the controversy regarding needle placement by using a traditional intraplexus technique at the interscalene groove and comparing it with the recently described periplexus approach. ${ }^{11}$ We examined the ink deposits in the tissues as a marker of the deepest layer of needle tip penetration 
into the neural tissue at the time of injection in the cadavers using these two techniques. We hypothesized that the periplexus approach would result in a reduced rate of subepineurial injection compared with the intraplexus technique.

\section{Methods}

Both the Capital District Health Authority Research Ethics Board and the Dalhousie University Research Ethics Board gave approval for the initial pilot study in March 2012 and for the present study in July 2013. Two clinical grade cadavers were used for the pilot study, and twenty-six clinical grade cadavers were used for the main study.

\section{Cadaver preparation}

Following surface disinfection, cadavers were embalmed $\left(950 \mathrm{~mL} \cdot \mathrm{min}^{-1}\right.$ at 18 pounds per square inch) using a commercial embalming machine (Dodge Co., Mississauga, ON, Canada) and a two-stage process. The primary solution (3 L) contained 5\% potassium acetate (Fisher Scientific, Ottawa, ON, Canada) and $17 \%$ glycerol (Univar, Dartmouth, NS, Canada) in warm water. The secondary solution $(3.74 \mathrm{~L})$ contained $6.5 \%$ commercial arterial embalming chemical (B4, Hydrol Chemical Co., Yeadon, PA, USA) in warm water. After embalming, the cadaver was washed thoroughly, catalogued, and wrapped in flannel sheets moistened with a solution of $1.5 \%$ phenol (VWR, Mississauga, ON, Canada), 9.5\% ethanol (Commercial Alcohols, Toronto, ON, Canada), and $11 \%$ glycerol in water to prevent mold growth and to slow dehydration. The cadaver was placed in a sealed pouch and kept at $4^{\circ} \mathrm{C}$ until use.

We commenced with a two-phase pilot study a) to ensure that the embalming process did not affect the permeability of the tissue to ink and b) to test our ability to perform ultrasound-guided injections and obtain histology with clinical grade cadavers.

For phase 1 of the pilot study, the ulnar nerves were exposed and left in situ from mid arm to the wrist, and each side was dedicated to either an intraneural or an extraneural injection. For intraneural injections, India ink $(0.1 \mathrm{~mL})$ was injected manually under direct vision at two sites by inserting an EchoStim needle $30^{\circ}$ to the surface. For extraneural injections, India ink $(0.1 \mathrm{~mL})$ was deposited externally and left to settle for $60 \mathrm{~min}$ at four different sites along the ulnar nerve. All regions of the ulnar nerve injected or incubated with India ink were then washed with saline, fixed in $10 \%$ formalin for $24 \mathrm{hr}$, and prepared for histologic examination. All specimens bathed in ink had only external staining of the epineurium, whereas deliberate injection into the nerve showed ink below either the epineurium or the perineurium. Consequently, the India ink was considered an accurate marker of needle tip position.

For phase 2 of the pilot study, we imaged the brachial plexus of a second cadaver at two levels, the interscalene groove and the supraclavicular space as well as the median nerve using an Esaote Model 7340 ultrasound system and an LA 435 high-frequency probe (Esaote NA Inc, Indianapolis, IN, USA). We performed an in-plane technique by placing an EchoStim Facet Tip 21G 50-mm echogenic needle (MED-RX, Oakville, ON, Canada) in a periplexus or intraplexus position at each location, and intraneural or perineural for the median nerve. Six needle placements (three intraneural and three extraneural) were completed, and India ink $(0.1 \mathrm{~mL})$ was injected/deposited at each site. The brachial plexus and median nerve were then dissected, removed for histological preparation, coded, and analyzed microscopically.

The $0.1 \mathrm{~mL}$ volume of ink was chosen based on previously reported methodology which showed that 0.1 $\mathrm{mL}$ accurately determined needle tip location, whereas a greater volume resulted in gross staining of all surrounding structures. ${ }^{15}$ As we were interested only in needle tip position and not the extent of injectate spread, we did not inject volumes that are generally required to achieve nerve blockade in live subjects. Furthermore, hydrodissection (with saline or dextrose solutions) to visualize the needle tip was not performed so as not to dilute the ink. The EchoStim Facet Tip needle was inserted at a shallow angle, in plane with the ultrasound beam. The needle has four rows of corner cube reflectors that allow excellent visualization of the needle tip. ${ }^{17}$

We found that ultrasound visualization and tactile feedback with needle advancement through tissue and fascia planes was equivalent to performing the technique in live patients. In keeping with previous research, ${ }^{18,19}$ we observed that a small volume $(0.1 \mathrm{~mL})$ of ink could be observed on ultrasound to expand tissue. Our results for the second cadaver showed ink localized to an extra-epineurial location with a periplexus (i.e., brachial plexus injection site) or perineural technique (i.e., median nerve injection site). Ink was found to be subepineurial with the intraplexus/median nerve injections.

Following the analysis and confirmation of our techniques in the pilot study, we went on to study an additional 26 cadavers. One injection technique (periplexus or intraplexus) was performed at the interscalene position, while the remaining technique was subsequently performed on the contralateral side of each cadaver. Side, order, and technique were assigned randomly using a random number table for a total of 52 injections using 26 cadavers (Fig. 1). 


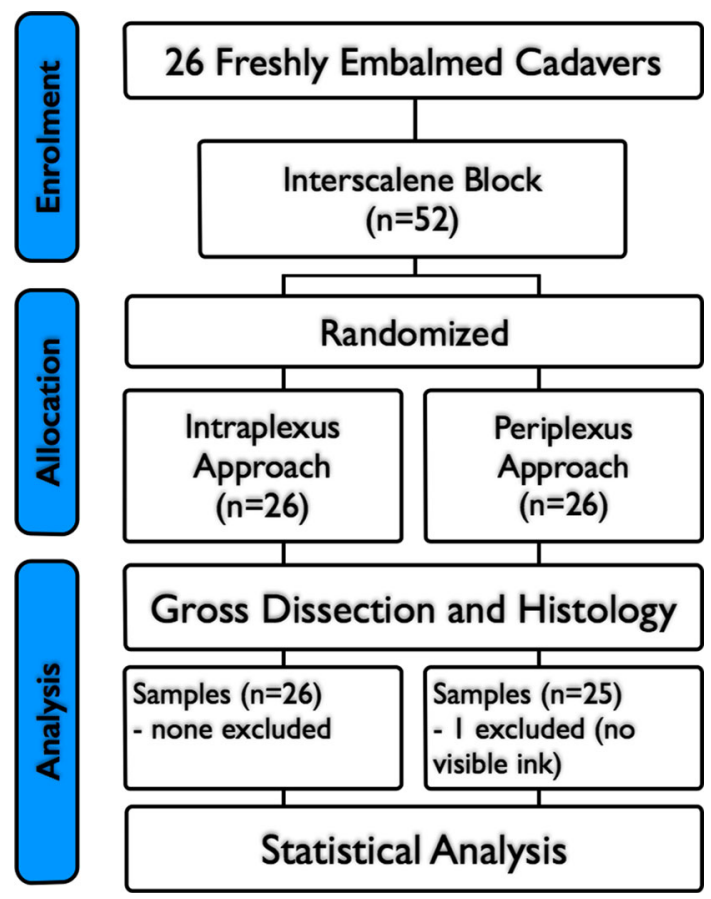

Fig. 1 CONSORT diagram

One person (J.G) performed all ultrasound-guided injections while being observed by a single experienced regional anesthesiologist (J.S.). For all injections, an EchoStim 21G 50-mm needle was inserted in plane to ultrasound beam using an Esaote MyLab Touch ultrasound machine with its SL3235, 6-18 MHz linear transducer. The frequency of the probe was set to $18 \mathrm{MHz}$, and the needle was primed with a $1 \mathrm{~mL}$ syringe that contained $0.1 \mathrm{~mL}$ of Black India FW Acrylic Ink (Daler-Rowney, Bracknell, England).

Spence et al. have previously described the injection technique for the interscalene brachial plexus. ${ }^{11}$ The intraplexus approach involved advancing the needle tip in plane at a shallow angle to the ultrasound probe, from lateral to medial, and through the middle scalene muscle and its investing fascia to position the tip between the hypoechoic roots. The intraplexus location was further confirmed by a "visual and physical popping sensation"11 as the needle penetrated the sheath. A deliberate attempt was made to avoid direct needle to nerve root contact for all brachial plexus injections (Fig. 2A; Link 1\&2, available as Electronic Supplementary Material). The periplexus technique involved the same in-plane approach, bringing the needle tip next to but not through the lateral hyperechoic border of the plexus. Once the needle tip was placed at the intended location, the ink $(0.1 \mathrm{~mL})$ was injected while observing the spread of the injectate (Fig. 2B; Link 3\&4, available as Electronic Supplementary Material).

For each injection, two still images were recorded: one prior to needle insertion of the site and one with the needle

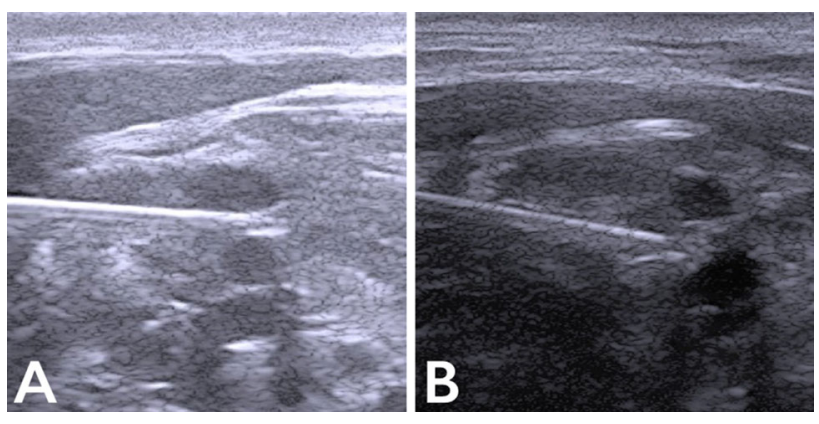

Fig. 2 A) Static ultrasound image of intraplexus needle tip location (A), periplexus needle tip location (B)

at the target. Two videos were also created for each injection: one video of the needle reaching the target and one video of the ink injection with the needle at the target. All four recordings were assigned one number code chosen randomly and linked to the cadaver, injection technique, and histology slide numbers. The number codes were kept on a master list not available to the reviewers of the histology slides during the study.

Two experienced regional anesthesiologists (G.L., C.D.), not present at the time of injection and blinded to the technique, reviewed all video recordings. They assessed whether the needle tip was intraplexus or periplexus using the four recordings for each injection. The distance from needle tip to the closest hypoechoic fascicle was measured from the recorded images prior to injection. In addition, for the periplexus technique, the distance from the needle tip to the lateral edge of the plexus was also measured from the recorded images.

After the injections were completed, the brachial plexus was dissected via an incision $2 \mathrm{~cm}$ posterior and parallel with the lateral border of the sternocleidomastoid muscle. The investing and prevertebral layers of the deep cervical fascia were removed to expose the anterior and middle scalene muscles. An incision was then made parallel to the track of the injection needle to the depth of the cervical spine 1-2 cm above and below the visible needle entry site. The entire block of tissue containing the anterior and middle scalene muscles as well as the brachial plexus was then removed.

Immediately following dissection, the specimen was prepared for histologic examination. The tissues were soaked in $10 \%$ neutral buffered formalin (Fisher Scientific, Whitby, ON, Canada). Once hardened, they were trimmed further until ink was observed and placed in labelled cassettes for histological processing. All specimens were post-fixed in $10 \%$ neutral buffered formalin for one week.

After fixation, the tissue was washed, dehydrated, and infiltrated with paraffin (Leica ASP 300 Tissue Processor, Lica Biosystems, Concord, ON, Canada) and mounted 


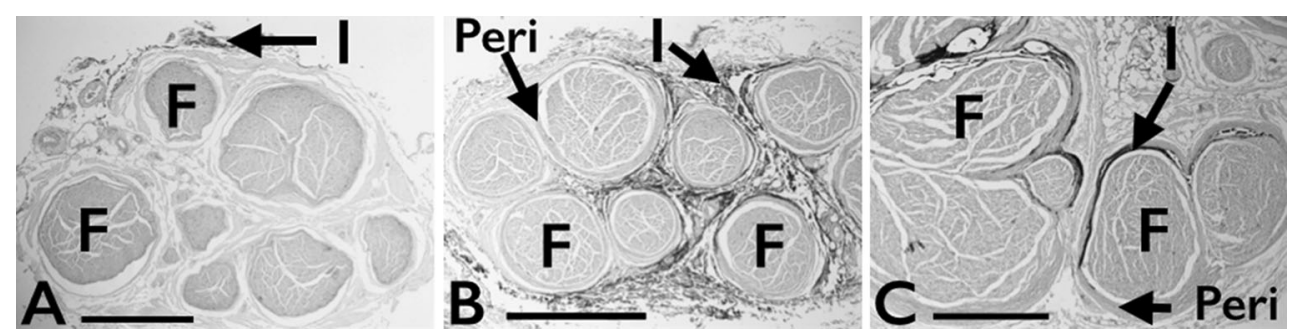

Fig. 3 Ultrasound-guided injections of the median nerve showing extra-epineurial (A), subepineurial but extra-perineurial (B), and subperineurial $(C)$ ink distribution. $\mathrm{F}=$ fascicle; $\mathrm{I}=\mathrm{ink}$; Peri = perineurium; Scale $=1 \mathrm{~mm}$

within paraffin blocks (Leica EG1150H/C Tissue Embedding Center). A microtome (Leica RM2255) was used to cut $10 \mu \mathrm{m}$ sections that were then mounted on glass slides (Fisher Scientific). The slides were allowed to dry overnight at $45^{\circ} \mathrm{C}$ and were then deparaffinized, stained with hematoxylin and eosin, mounted (Cytoseal XYL, Richard-Allan Scientific, MI, USA), and coverslipped. All slides were coded with a random number, thereby blinding the examiners (J.G. and J.S.) of the slides to the source of the tissue. Slides were examined directly using an Olympus SZ40 stereo microscope (Olympus Optical Co, Japan). Photomicrograph images were captured using a Axiocam HRC Color Camera (Carl Zeiss Canada, Toronto, ON, Canada).

As the aim of this study was to determine the exact location of the needle tip in relation to the surrounding nerve layers, we avoided the ambiguous terminology of describing the histology as intraneural or extraneural. ${ }^{5}$ Accordingly, the presence of ink was evaluated using one of two qualitative criteria (Fig. 3):

1. Extra-epineurial: ink exterior to epineurium and no ink seen between fascicles. The epineurium was defined as the fibroadipose tissue that surrounds bundles of fascicles.

2. Subepineurial: ink found either between fascicles within loose connective tissue or below perineurium. The perineurium was defined as a dense layer of cells that sheathes each fascicle. Furthermore, we defined ink below the perineurium (subperineurial) as intrafascicular.

Where disagreement occurred, an anatomist (W.B.) experienced in neuropathology reviewed the slides and made the final decision.

Our primary endpoint was the incidence of histological samples with subepineurial ink upon microscopic examination. Secondary endpoints included sonographical assessment of the needle tip to both the nearest fascicle and the lateral border aligning the fascicles. As well, we reviewed the videos of the blocks being performed and determined the level of agreement between the blinded observers and the anesthesiologist administering the block as to which technique was used in each case.
Statistical analysis

Cadaver neck measurements were normally distributed and are presented as mean (SD). Agreement of interobserver variability was analyzed using Cohen's Kappa statistic. Needle to nerve distances were not normally distributed and are presented as median [interquartile range; IQR] and analyzed after $\log$ transformation with the Student's $t$ test. The location of ink on histology is presented as categorical data. The two-sided Fisher's exact test was used to analyze the odds ratio (OR) of the histological data with a significance level of 0.05 . All analyses were performed using R statistical software ( $\mathrm{R}$ Core Team, 2014; R Foundation for Statistical Computing, Vienna, Austria).

Our sample size calculation was based on a binary outcome (i.e., subepineurial ink or not), assuming a power of 0.8 , an alpha of 0.05 , and a $50 \%$ previously reported incidence of subepineurial ink with an intraplexus approach. ${ }^{15}$ We determined that a clinically significant reduction with a periplexus approach to $5 \%$ subepineurial ink or less would require 13 injections per group $(n=26)$.

\section{Results}

There were 13 female and 13 male cadavers in this study. The mean (SD) neck circumference measurements for the 13 female cadavers and 11 of the 13 male cadavers were $34.9(4.6) \mathrm{cm}$ and $38.8(2.5) \mathrm{cm}$, respectively. There were 26 intraplexus and 26 periplexus injections performed. One periplexus technique could not be analyzed for histological needle tip position due to lack of visible ink on the slide review. There was substantial agreement between the blinded video assessors and the investigators' intended experimental needling technique (Cohen's Kappa Statistic = $0.92, P<0.0001)$

The median [IQR] measurements from needle tip to the closest hypoechoic fascicle did not differ significantly between the two techniques (intraplexus 0.6 [0.4-0.9] mm; periplexus $0.7[0.5-0.9] \mathrm{mm} ; P=0.767$ ). For the periplexus technique, the median [IQR] distance from needle tip to the lateral border of the brachial plexus was $0.4[0.2-0.5] \mathrm{mm}$. 

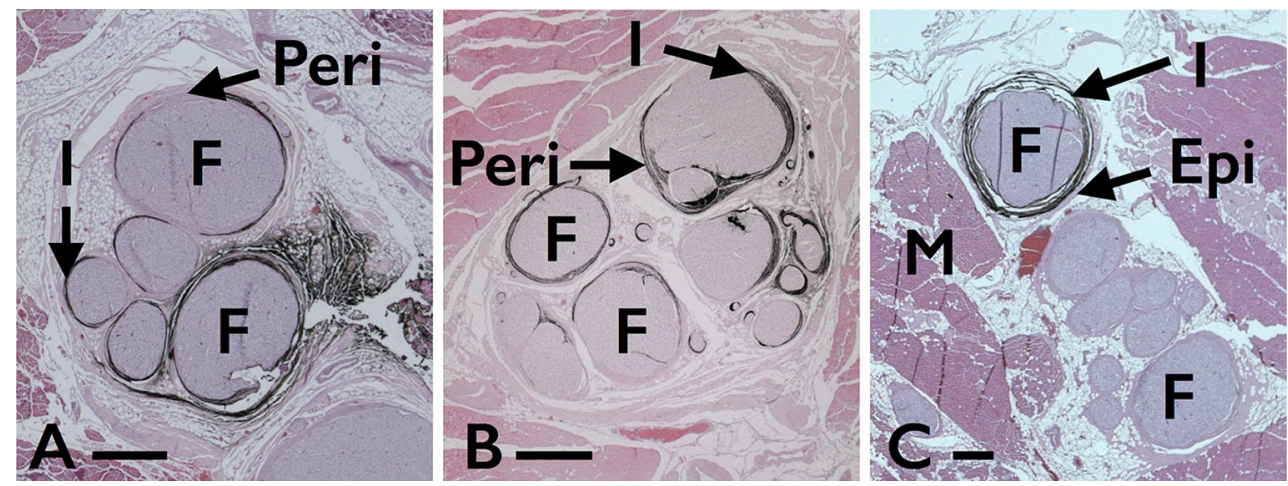

Fig. 4 Ultrasound-guided intraplexus interscalene approach demonstrating subperineurial $(\mathrm{A}$ and $\mathrm{B})$ and subepineurial $(\mathrm{C})$ ink distribution. $\mathrm{F}=$ fascicle; $\mathrm{I}=$ ink; Peri $=$ perineurium; Epi $=$ epineurium; $\mathrm{M}=$ muscle; Scale $=1 \mathrm{~mm}$

Table Histological location of ink based on intended injection technique

\begin{tabular}{lllcc}
\hline $\begin{array}{l}\text { Intended Injection } \\
\text { Technique }\end{array}$ & $\begin{array}{l}\text { Number of Injections Available } \\
\text { for Histologic Examination }\end{array}$ & Subperineurium & Subepineurium & $\begin{array}{l}\text { Extra- } \\
\text { epineurium }\end{array}$ \\
\hline Intraplexus & 26 & $2(7.7 \%)$ & $1(3.8 \%)$ & $\begin{array}{l}\text { Intramuscular } \\
\text { only }\end{array}$ \\
Periplexus & 25 & $0(0.0 \%)$ & $0(0.0 \%)$ & $3(11.5 \%)$ \\
\hline
\end{tabular}

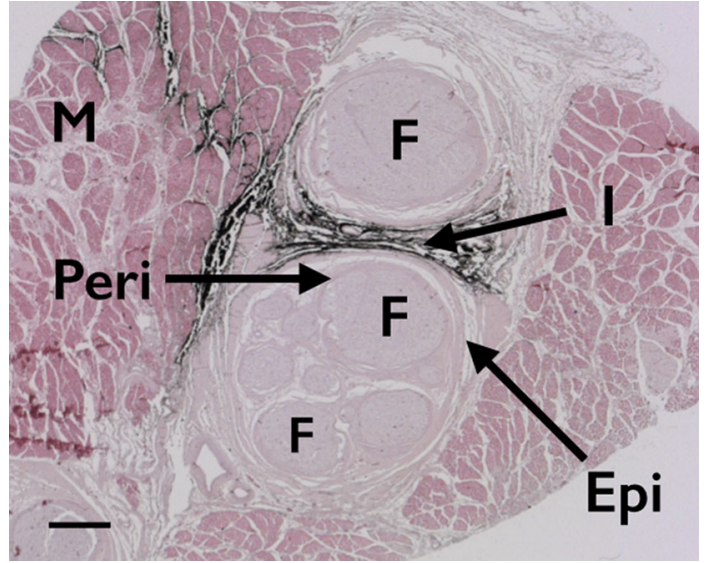

Fig. 5 Ultrasound-guided intraplexus approach showing extraepineurial ink distribution between two nerve roots with no subepineurial ink. $\mathrm{F}=$ fascicle; $\mathrm{I}=$ ink; Peri = perineurium; $\mathrm{M}=$ muscle; Scale $=1 \mathrm{~mm}$

For the intraplexus technique, $2 / 26(7.7 \%)$ injections resulted in subperineurial ink and 1/26 (3.8\%) resulted in subepineurial ink (Fig. 4). Therefore, 3/26 (11.5\%) injections met our definition of ink located at least below the epineurium (Table). Three intraplexus injections resulted in ink found only in muscle without any staining of the external surface of epineurium. Therefore, 23 $(88.5 \%)$ of the 26 injections resulted in extra-epineurial ink (Fig. 5, Table).

For the periplexus technique, all 25 analyzed injections were extra-epineurial. Ink was found only in muscle in $17 / 25(68 \%)$ injections without any staining of the external

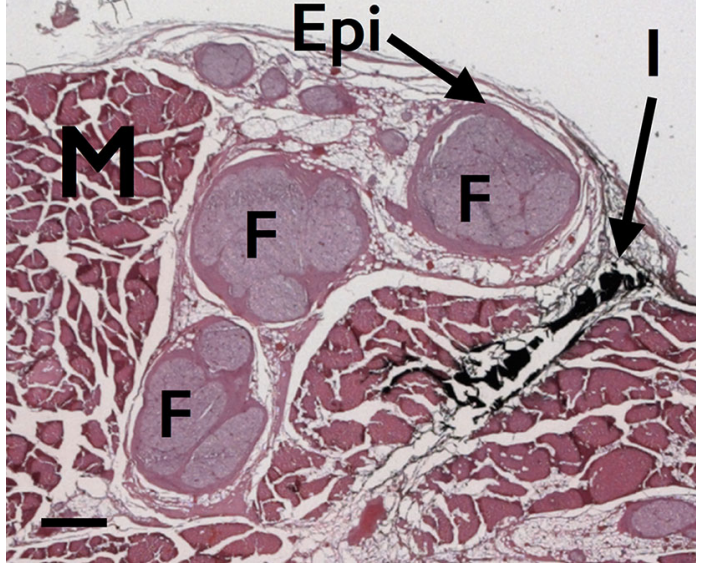

Fig. 6 Ultrasound-guided periplexus interscalene approach showing extra-epineurial and intramuscular ink. $\mathrm{F}=$ fascicle; $\mathrm{I}=$ ink; Epi $=$ epineurium; $\mathrm{M}=$ muscle; Scale $=1 \mathrm{~mm}$

surface of the epineurium. The remaining eight injections showed ink staining the external surface of the epineurium (Fig. 6).

We were unable to show that the injection technique (periplexus or intraplexus) affected the rate of subepineurial ink deposits (OR, $0 ; 95 \%$ confidence interval, 0 to 2.362; $P=0.235)$.

\section{Discussion}

Of the 52 injections performed in this study, no subepineurial ink deposits were observed in the 
periplexus group, whereas subepineurial ink deposition was observed in $3 / 26(11.5 \%)$ intraplexus injections. We were confident that we met the criteria of a periplexus $v s$ intraplexus technique as a) there was a high level of agreement with the blinded video reviewers and b) our measurements of needle tip showed close proximity to the lateral border of the brachial plexus (periplexus approach) or the roots in both techniques. Nevertheless, we were unable to demonstrate a significant difference in the incidence of subepineurial injection between an intraplexus $v s$ a periplexus approach. As our subepineurial rate with the intraplexus approach was substantially lower than expected, we were underpowered to determine a difference.

Our study results show a substantially lower intraplexus subepineurial injection rate compared with a study by Orebaugh et al., $11.5 \%$ vs 50\%, respectively; we based our power calculations on this study. The difference in study results can be explained by the disparate interpretations of the anatomy on histology. Orebaugh et al. demonstrate their conceptualization of the boundaries of the epineurium with a drawing of an amorphous epineurium surrounding the fascicles. They interpreted any visible ink deeper than the subfascial space as subepineurial. We observed a histologically distinct epineurium surrounding each root and embedded in loose connective tissue (Fig. 5). Similar to Franco, ${ }^{13,14}$ we interpreted the ink outside this distinct layer surrounding the roots as extra-epineurial, which is where most of our intraplexus injections occurred.

Three intraplexus injections resulted in ink staining only muscle, perhaps because the fascia between the middle scalene muscle and the brachial plexus can be quite dense and occasionally require substantial force to penetrate. When this force was applied, it is possible that the needle could have penetrated the lateral fascia through the tissue space between the nerve roots and then penetrated the medial fascia to the anterior scalene muscle. Whereas Orebaugh et al. did not observe any subperineurial deposits in their study, we observed subperineurial ink in two intraplexus injections. Indeed, in these two subperineurial cases, ink was found to involve all fascicles of the root with little spread through the extra-perineurial space. This may show the interconnectedness of the fascicles and indicate that an injection of only $0.1 \mathrm{~mL}$ of volume into the largely non-compliant space may lead to distant spread through the subperineurial network.

Although there is debate regarding the danger of subepineurial injection with low injection pressure and volume, ${ }^{7,20,21}$ there is consensus that subperineurial injection is harmful and should be avoided. ${ }^{8-10,22}$ Despite our best efforts to avoid the hypoechoic roots using a standard approach under ultrasound guidance, it is alarming that two subperineurial (intrafascicular) injections occurred with the intraplexus technique. There are two explanations why this may have occurred: 1) operator difficulty to view the needle tip at all times and 2) the limitations of ultrasound or the operator to visualize all anisotropic fascicles and nerve layers within the interscalene groove.

Our needle tip to fascicle distances was similar for both the intraplexus and periplexus approaches. Furthermore, for the periplexus approach, our average needle tip distance was substantially closer to the brachial plexus border $(0.4$ $\mathrm{mm}$ ) than the $1.6 \mathrm{~mm}$ shown to produce successful block in $95 \%$ of subjects. ${ }^{12}$ Despite our close proximity to neural elements, we were unable to find any evidence of subepineurial injection following the periplexus technique. Ink was found within the middle scalene muscle and not in direct contact with the epineurium in $17 / 25(68 \%)$ of our periplexus injections. This incidence of intramuscular injection does not show our inability to perform a clinically successful periplexus technique as much as it shows that avoiding penetration of the medial middle scalene fascia resulted in intramuscular injection while protecting the plexus from needle trauma. Importantly, the small volume of ink used was a marker of the deepest layer of needle tip penetration into the neural tissue at the time of injection and may not be indicative of where 10-20 mL of local anesthetic would have diffused.

Our study has some limitations. There was an insufficient sample size to show a difference between the two techniques given our lower than expected rate of subepineurial injection with the intraplexus technique. We cannot extrapolate that penetration of the perineurium in cadavers would lead to a clinically significant neurological deficit in live patients. Nevertheless, avoidance of "intraneural injection", which is defined by injection below the epineurium, is standard practice within the regional anesthesia literature. ${ }^{3,5,13,23}$ Nerves cannot be dissected and removed in live patients, while comparing block techniques requires thousands of patients due to the low but clinically significant rate of neurological complications. ${ }^{24}$ We chose the cadaver model followed by microscopic assessment of tissues in an attempt to clarify exactly which neural layers are penetrated with an intraplexus $v s$ a periplexus approach. Due to the small volumes of injectate used, we were unable to monitor opening injection pressure.

This is a substantial cadaveric histology study examining the risk of subepineurial injection with an interscalene brachial plexus block using two approaches. Based on a binary outcome (i.e., subepineurial or not) and assuming a power of 0.8 with an alpha 0.05 to show a $10 \%$ absolute reduction in subepineurial injection from a control (intraplexus) of $11 \%$ to experimental (periplexus) $1 \%$ would require 88 injections per group $(n=176)$. The need 
for such a large sample size would make a future study expensive and onerous to conduct. Nevertheless, this does not distract from the clinical relevance of this issue, as severe neurological complications can be devastating.

Our study found a small risk of subperineurial and subepineurial injection with the intraplexus technique. While we did not observe any subepineurial ink with the periplexus technique, the difference was not statistically significant so we cannot conclude that there is clearly less risk associated with the periplexus technique. Nonetheless, our results suggest that the periplexus technique may be superior and that further study is warranted. When these data are interpreted, with the recognition that interscalene brachial plexus block is associated with higher rates of neurological complications compared with other peripheral nerve blocks, ${ }^{25}$ we recommend that clinicians consider a periplexus technique rather than an intraplexus technique for interscalene brachial plexus block, especially if the success rate for both techniques is similar.

Acknowledgements We gratefully acknowledge the exceptional help provided to us by Pat Colp, Nancy McGrath, Heather Butler, Sara Whynot, Mike Mercer, and Esaote Canada. We also acknowledge the help of our colleagues, Drs. G. Launcelott, C. Delbridge, V. Uppal, and C. Prabhakar.

Funding This project was supported through the Capital Health District Research Fund, QEII Health Sciences Centre, Halifax, N.S. receiving a Category B grant of \$15,000.00 CAD in July 2013.

Conflicts of interest None declared.

\section{References}

1. Barrington MJ, Snyder GL. Neurological Complications of Regional Anesthesia. Curr Opin Anaesthesiol 2011; 24: 554-60.

2. Neal JM. Ultrasound-guided regional anesthesia and patient safety: An evidence-based analysis. Regional Anesth Pain Med 2010; 35: S59-67.

3. Choquet $O$, Morau D, Biboulet $P$, Capdevila X. Where should the tip of the needle be located in ultrasound-guided peripheral nerve blocks? Curr Opin Anaesthesiol 2012; 25: 596-602.

4. Van Geffen GJ, Moayeri N, Bruhn J, Scheffer GJ, Chan VW, Groen GJ. Correlation between Ultrasound Imaging, CrossSectional Anatomy, and Histology of the Brachial Plexus A Review. Reg Anesth Pain Med 2009; 34: 490-7.

5. Sala-Blanch X, Vandepitte C, Laur JJ, et al. A practical review of perineural versus intraneural injections: a call for standard nomenclature. Anesthesiol Clin 2011; 49: 1-12.

6. Cohen JM, Gray AT. Functional deficits after intraneural injection during block. Reg Anesth Pain Med 2010; 35: 397-9.
7. Lupu CM, Kiehl TR, Chan VW, El-Beheiry H, Madden M, Brull $R$. Nerve expansion seen on ultrasound predicts histologic but not functional nerve injury after intraneural injection in pigs. Reg Anesth Pain Med 2010; 35: 132-9.

8. Hadzic A, Dilberovic F, Shah $S$, et al. Combination of intraneural injection and high injection pressure leads to fascicular injury and neurologic deficits in dogs. Reg Anesth Pain Med 2004; 29: 417-23.

9. Borgeat A. Regional anesthesia, intraneural injection, and nerve injury: beyond the epineurium. Anesthesiology 2006; 105: 647-8.

10. Kapur E, Vuckovic I, Dilberovic F, et al. Neurologic and histologic outcome after intraneural injections lidocaine in canine sciatic nerves. Acta Anaesthesiol Scand 2007; 51: 101-7.

11. Spence BC, Beach $M L$, Gallagher JD, Sites BD. Ultrasoundguided interscalene blocks: understanding where to inject the local anaesthetic. Anaesthesia 2011; 66: 509-14.

12. Albrecht E, Kirkham KR, Taffé $P$, et al. Maximum Effective Needle-to-Nerve Distance for Ultrasound-Guided Interscalene Block An Exploratory Study. Reg Anesth Pain Med 2014; 39: 56-60.

13. Franco C. Connective Tissues Associated With Peripheral Nerves. Reg Anesth Pain Med 2012; 37: 363-5.

14. Franco C. Reply to Orebaugh et al. Reg Anesth Pain Med 2013; 38: 71.

15. Orebaugh SL, McFadden $K$, Skorupan H, Bigeleisen PE. Subepineurial Injection in Ultrasound-Guided Interscalene Needle Tip Placement. Reg Anesth Pain Med 2010; 35: 450-4.

16. Orebaugh SL, Bigleisen PE, McFadden K. Connective tissue and peripheral nerves. Reg Anesth Pain Med 2013; 38: 70-1.

17. Edgcome H, Hocking G. Sonographic identification of needle tip by specialists and novices: a blinded comparison of 5 regional block needles in fresh human cadavers. Reg Anesth Pain Med 2010; 35: 207-11.

18. Moayeri N, Krediet AC, Welleweerd JC, Bleys RL, Groen GJ. Early ultrasonographic detection of low-volume intraneural injection. Br J Anaesth 2012; 109: 432-8.

19. Jens Kessler J, Moriggl B, Grau T. Ultrasound-guided regional anesthesia: learning with an optimized cadaver model. Surg Radiol Anat 2014; 36: 383-92.

20. Bigeleisen PE. Nerve puncture and apparent intraneural injection during ultrasound-guided axillary block does not invariably result in neurologic injury. Anesthesiology 2006; 105: 779-83.

21. Robards C, Hadzic A, Somasundaram L, et al. Intraneural injection with low-current stimulation during popliteal sciatic nerve block. Anesth Analg 2009; 109: 673-7.

22. Farber SJ, Saheb-Al-Zamani M, Zieske L, et al. Peripheral nerve injury after local anesthetic injection. Anesth Analg. 2013; 117: 731-9.

23. Steinfeldt $T$, Schwemmer $U$, Volk $T$, Neuburger $M$, et al. Nerve localization for peripheral regional anesthesia. Anaesthesist. 2014; 63: 597-602.

24. Neal JM, Wedel DJ. Ultrasound guidance and peripheral nerve injury: is our vision as sharp as we think it is? Reg Anesth Pain Med 2010; 35: 335-7.

25. Brull R, McCartney CJ, Chan VW, El-Beheiry H. Neurological complications after regional anesthesia: contemporary estimates of risk. Anesth Analg 2007; 104: 965-74. 